\title{
Confronting chemobrain: an in-depth look at survivors' reports of impact on work, social networks, and health care response
}

\author{
Nelli Boykoff • Mona Moieni • \\ Saskia Karen Subramanian
}

Received: 22 July 2008 / Accepted: 18 August 2009/Published online: 16 September 2009

(C) The Author(s) 2009. This article is published with open access at Springerlink.com

\begin{abstract}
Introduction Mild cognitive impairment following chemotherapy is one of the most commonly reported post treatment symptoms by breast cancer survivors. This deterioration in cognitive function, commonly referred to as "chemobrain" or "chemofog," was largely unacknowledged by the medical community until recent years. Although chemobrain has now become the subject of more vigorous exploration, little is known about this specific phenomenon's psychosocial impact on breast cancer survivors. This research documents in-depth the effects that cognitive impairment has on women's personal and professional lives, and our data suggest that greater attention needs to be focused on this arena of survivorship. Methods The results are based on an in-depth qualitative study of 74 white and African American breast cancer survivors in California who experience post-treatment side effects. The data reported herein were obtained through the use of focus groups and in-depth interviews.
\end{abstract}

Funding for this research was provided by the Susan G. Komen Foundation

N. Boykoff

Mayo Medical School,

Rochester, MN, USA

M. Moieni

UCLA Center for Culture and Health, University of California, Los Angeles,

Los Angeles, CA, USA

S. K. Subramanian $(\bowtie)$

Department of Psychiatry and Biobehavioral Sciences,

UCLA Center for Culture and Health, Semel Institute,

University of California, Los Angeles,

760 Westwood Plaza, Box 62, Los Angeles, CA 90024-1759,

USA

e-mail: saskia@ucla.edu
Results Our data indicate that cognitive impairment can be problematic for survivors, with many asserting that it is their most troublesome post treatment symptom. Survivors report diminished quality of life and daily functioning as a result of chemobrain. Respondents detail a range of coping strategies that they are forced to employ in order to manage their social and professional lives.

Discussions/conclusions Chemobrain significantly impairs a proportion of cancer survivors, at great cost to them economically, emotionally, and interpersonally. This suggests that more research needs to be conducted on the psychosocial ramifications of post treatment symptoms in order to inform the efforts of the medical and mental health communities as well as the support networks of survivors. Implications for cancer survivors A better and broader understanding of the effects of cognitive impairment both in the medical community and among lay people could pave the way for improved social and psychological services for this population.

Keywords Breast cancer survivor - Chemobrain . Chemotherapy effects · Cognitive impairment .

Psychosocial $\cdot$ Qualitative

\section{Introduction}

An increasing number of women survive breast cancer. Of the 11.4 million cancer survivors in the United States alone, female breast cancer survivors represent the largest population at $23 \%$, or 2.6 million women [1]. Although breast cancer is the second leading cause of cancer death in women, mortality rates have declined steadily since about 1990 [2]. However, survival may come at a cost for some, as biomedical researchers have begun to acknowledge that 
cancer treatment itself (surgery, radiation, chemotherapy) can result in long-term physiological damage, which in turn can vastly impact quality of life. One post-treatment side effect that has received growing medical attention is popularly referred to as "chemobrain." This condition encompasses a range of symptoms such as memory loss, inability to concentrate, difficulty in thinking, and other subtle, cognitive changes. Although the severity of cognitive difficulty varies among patients, the slightest deterioration in cognitive function can be devastating for the patient's quality of life [3]. It is currently unknown exactly how many breast cancer survivors suffer from this condition, and anecdotal evidence suggests that the phenomenon may even affect a broad array of cancer survivors beyond those who experienced breast cancer. Although some current biomedical cancer studies do seek to understand the nature and etiology of chemobrain, there is a dearth of information about its psychosocial ramifications-how do individuals suffering from this condition experience the symptoms? How does it impact their lives and functioning? To what extent is their daily experience compromised?

A growing body of research examines cognitive dysfunction in breast cancer patients who have undergone standard-dose chemotherapy. A study by Wieneke and Dienst [4] analyzed 28 participants who were treated for early-stage breast cancer with either CMF chemotherapy, CAF chemotherapy, or a combination of the two. A series of neuropsychological tests were performed in order to determine any affect on cognitive functioning. Their results indicated that $75 \%$ of the participants suffered from cognitive impairment on one or more neuropsychological tests. A study conducted by Schagen et al. [5] of thirty-nine breast cancer patients treated with adjuvant (CMF) chemotherapy showed that $28 \%$ had deficits in the areas of concentration and memory versus $12 \%$ of the thirty-four patients in the control group who did not receive adjuvant chemotherapy. Van Dam et al. [6] correlated the level of cognitive impairment with the dosage of adjuvant chemotherapy. Their results showed that $32 \%$ of patients who had undergone high-dose chemotherapy were affected adversely with respect to cognitive functioning while only $17 \%$ of the patients who were given a standard dose of chemotherapy were adversely affected, demonstrating a dose response rate. Brezden et al. [7] surveyed 3 groups of women: group A consisted of breast cancer patients undergoing adjuvant chemotherapy, group B consisted of women who had finished chemotherapy treatment on average of 2 years ago, and group $\mathrm{C}$ consisted of healthy controls. Women in both groups A and B suffered more cognitive dysfunction than those in group $\mathrm{C}$; furthermore, group A proved to have greater cognitive deficits than group B. Ahles et al. [8] reviewed the cases of breast cancer or lymphoma survivors who had been diagnosed and treated with chemotherapy in the previous 10 years. The study indicated that cognitive deficits were still present even a decade after treatment and that patients treated with adjuvant chemotherapy were much more likely to perform poorly on neuropsychological tests than patients who had undergone local therapy only. A later study by Castellon et al. [9] further confirmed these previous findings, again reaffirming that chemotherapy negatively impacts neurocognitive functioning.

Since 2004, the number of studies investigating posttreatment cognitive impairment has significantly increased. In 2005, Shilling et al. [10] published the preliminary results of their longitudinal study of patients who had received chemotherapy and compared their cognitive function to that of healthy controls. Of the chemotherapy patients, 34\% showed a decline in cognitive function versus $18.6 \%$ of the control group. In 2006, Bender et al. [11] found that women who received chemotherapy exhibited deteriorations in working memory compared to the control group. Another 2006 study [12] evaluated subjects' cognitive function before chemotherapy and 6 months after completing chemotherapy; $25 \%$ of the subjects exhibited cognitive decline from the baseline cognitive test. According to a 2006 article by Raffa et al.[13], chemobrain's existence has been "well established," even if a direct causal relationship has not been indisputably proven. Thus, many in the medical community have generally accepted the existence of post-treatment cognitive impairment, although the mechanism of the phenomenon is still unknown. Since 2007, numerous studies have sought to uncover this mechanism, and the exponential growth in research investigating chemobrain will undoubtedly continue in the coming years [14-18].

It should be noted, however, that although numerous studies have shown cognitive dysfunction in patients who have undergone chemotherapy, many of these studies did not assess the baseline cognitive function of patients before they underwent chemotherapy. In fact, a 2004 study that did assess baseline function found that $35 \%$ of women demonstrated cognitive impairment before the initiation of chemotherapy for their breast cancer, underscoring the importance of establishing pre-chemotherapy baseline cognitive functioning to accurately assess whether or not chemotherapy is indeed responsible for their cognitive decline [19]. Additionally, some studies researching chemobrain have concluded that there was no statistically significant difference in domains such as attention, cognition, or language between breast cancer patients who received chemotherapy and those who did not [20, 21]. Another study looked into the relationship between selfreported and objective cognitive dysfunction in breast cancer patients treated with adjuvant therapy. It found that self-reported memory and concentration problems were actually associated with psychological distress, rather than 
true cognitive decline as assessed by objective cognitive testing [22]. Data from more recent studies suggest that chemobrain may be more complex in its etiology, caused not solely by chemotherapy treatment but potentially also precipitated by the "impact of surgery and anesthesia, hormonal therapy, menopause, anxiety, depression, fatigue, supportive care medications, genetic predisposition, comorbid medical conditions, or possibly paraneoplastic phenomenon" [23]. Cited as problematic in this body of research is the lack of standard measures of cognitive impairment and small sample sizes. Certainly, overall, while there is no definitive understanding of chemobrain, there is consensus that there is yet a need for large, multi-center studies to further explore this phenomenon.

Although the controversy over chemobrain persists, survivors continue to report post-chemotherapy cognitive changes, and a significant body of research validates the existence of cognitive impairment experienced by breast cancer survivors subsequent to chemotherapy. A 2005 meta-analysis of chemobrain literature concluded that cognitive impairment was indeed a reality for many breast cancer survivors who underwent chemotherapy [24]. Indeed, the health care community has already begun an examination of chemobrain's effects on patients' lives. A 2005 article by Matsuda et al. [25] recognized that the "principle negative effect" of this mild cognitive impairment was "deterioration of quality of life." Citing a 2001 article by Bender et al. [26], Matsuda et al. noted that the most devastating effects are "for patients who hold professional and social positions." Despite the observation that cognitive impairment can have devastating effects on the personal and professional lives of women, there has been little discussion about the psychosocial ramifications of this condition. Both national and international media have become increasingly alerted to the quality of life problems that women with cognitive impairment experience [27, 28], and commercial products have been manufactured to help patients with chemobrain [29]. However, despite the media attention on the subject, only a small number of medical journals have detailed the direct effects of cognitive impairment on the lives of breast cancer patients $[22,30,31]$. There is, therefore, a paucity of literature focusing solely on the psychosocial effects of chemobrain, and our paper is one of the few in-depth descriptions of the psychosocial ramifications of chemobrain in the words of cancer survivors. Such literature needs to be available not only for breast cancer survivors, who may seek reassurance and often voice a longing for validation of their cognitive symptoms, but also for nurses and physicians, who need to better understand the sorts of changes their patients may be undergoing during and after chemotherapy so that they can be informed and compassionate providers for their patients.

\section{Methods}

The overarching investigation from which these data are drawn was designed as an exploratory pilot study that investigated post-treatment side effects of breast cancer survivors, detailing the range of symptoms, how women manage these symptoms, and the effects these symptoms have on women's personal and professional lives. These data were obtained from 74 women through the use of focus groups and in-depth interviews.

Adult subjects were at least 1 year beyond completion of adjuvant radiation and/or chemotherapy (some were continuing with Tamoxifen therapy). Recruitment occurred through the distribution and posting of flyers at various cancer wellness centers, physicians' offices, and support group meeting sites. Flyers, approved by the UCLA Institutional Review Board, included the following text (formatted and with graphics):

Are you a breast cancer survivor who has completed radiation or chemotherapy at least a year ago? Do you currently experience any sensations you believe may be related to your treatment, like fatigue, arthritis, memory loss, pain, or others? If you answered yes, then we would like the opportunity to speak with you. We are a UCLA based research team studying the range of post-treatment experiences of breast cancer survivors. We are also interested in understanding how people cope with post-treatment discomforts.

Respondents to the flyers were pre-screened by phone. The final sample included 36 African Americans and 38 Whites. Women were eligible to participate in focus groups and/or interviews; a total of 74 women were interviewed, and 20 participated in both the focus groups and interviews. Since respondents self-selected for the study based upon their subjective assessment of their post-treatment conditions, this is perforce a skewed sample. Given that we were conducting an exploratory investigation, however, we felt that the shortcomings of this recruitment strategy were acceptable and would allow us to access subjects most efficiently.

At the beginning of our research, we conducted four focus groups (6-8 participants each) in order to collect preliminary data and help refine our interview instrument. Subsequently, we conducted one in-depth interview (approximately $1-3 \mathrm{~h}$ in length) with each interview subject. Included in the interview instrument were sections eliciting data about the patients' medical background and treatment experience, the nature of their post treatment symptoms, reactions from medical personnel and from family and friends, the patients' self-management of the symptoms and the reactions of their providers, the strength of their social networks, and their evolving perceptions of self. To elicit data regarding symptoms, respondents were asked to self- 
report whether they were experiencing any from an extensive list; since the term "chemobrain" was then and is still unfamiliar to some survivors, we queried about cognitive impairment by asking separately whether they experienced loss of words, forgetfulness, memory loss, or chemobrain. Interviews and fieldnotes from the interview visit were tape recorded and transcribed.

Qualitative data were entered into computer files as the research progressed. Data in these forms consist of large verbal texts that must be interpreted, organized, and summarized using some text based analysis technique. A number of such techniques exist [32] which differ primarily in how the original texts are coded for subsequent sorting and organization. The technique most appropriate to our data and research goals is ethnographic content analysis referred to by Crabtree and Miller [32] as template text analysis. Essentially, this technique involves the creation of a code book based on variables identified by the researcher at the beginning of the study as relevant to the research questions and goals. Texts are read and codes are assigned to relevant portions of the text and entered. Code categories can be revised, expanded, and created as the research progresses. This requires that coding proceed from the very beginning of the research and that previously coded materials are updated as the coding is refined. The codes were ultimately managed using HyperResearch software.

The process of coding allows for the thematic analysis of data. Of some concern, however, is the validity of qualitative data that have been processed by a single researcher. To address this, the use of multiple coders has become a more common practice in qualitative studies, as has the consensus based review process which allows a group of coders to regularly review their identification of themes and codes. This study employed the skills of four trained coders in addition to input from the project director and the principal investigator. The entire research team met on a bi-weekly basis during the coding process and divergent ratings were assessed and discussed. In having a number of coders identify both the themes found within the texts as well as the representative quotes illuminating these themes and in subjecting the process to scrutiny by our entire team in a group setting resulted in a carefully constructed and analyzed dataset.

Though our sample is relatively small for any sort of complex quantitative analysis, we did enter quantifiable data into an SPSS database and compiled descriptive univariate and multivariate statistics. Table 1 details various demographic and treatment data.

\section{Results}

Women in our study reported, on average, 15 discrete, chronic symptoms that they attributed to their cancer treatment; of these symptoms, cognitive impairment was one of the most frequently documented $(70 \%)$. Other studies of breast cancer survivors report a wide range of prevalence of this specific symptom, typically from 10 $40 \%$. A University of Rochester Medical Center study of 595 cancer survivors across the US, however, reported a rate of $76 \% 6$ months after completion of treatment [33]. Effects of this condition were wide ranging and considered most troublesome by respondents. The following sections delineate the experiences of survivors in our study who were living with cognitive impairment. These experiences are discussed in terms of the general psychosocial influence of the symptoms, impact on interactions with medical providers, ramifications on social networks, consequences to work and economic well-being, and coping strategies employed by these women.

\section{General descriptions of chemobrain/psychosocial impact}

A variety of cognitive changes experienced by respondents in our study were defined as "frustrating" and "upsetting." Some women described being frightened by their diminished ability to retain material or to digest new information and recognized that they were not functioning as they once did.

- You have to fight to make yourself remember numbers, words, places that you go. Sometimes I would leave the house to go somewhere and I really couldn't remember how to get there... it almost made me break down because of the fact that you think you're losing your mind.

- ...I can remember just sitting there and thinking, 'My brain is just absolutely dead. I don't think I'll ever be able to think again.' And finding it very frightening... I do remember almost being panicked that I would never be able to think of words again, [that] I wouldn't function.

- ...it's not like I'm suddenly acting retarded or a dull normal. I'm still able to function. It's just the fine degree of memory or the speed at which I'd be able to recall information.

- I can't read technical books anymore. I just don't understand them. I'll read the same page over and over and over again and it just doesn't make sense. So I can't self-teach the way I used to be able to...I [also] don't read philosophy books anymore. I don't read books about politics or historic analysis or critiques. My reading is a lot lighter.

Other women faced diminished independence, becoming limited in their ability to manage certain responsibilities or get around. These types of changes led women to feel scared, dependent, and emotionally drained. 
Table 1 Descriptive data of respondents $(N=74)$

\begin{tabular}{|c|c|}
\hline Variable & Valid \% \\
\hline \multicolumn{2}{|l|}{ Age } \\
\hline $30-39$ & 2.8 \\
\hline $40-49$ & 22.5 \\
\hline $50-59$ & 42.5 \\
\hline $60-69$ & 21.1 \\
\hline $70-79$ & 8.5 \\
\hline $80-89$ & 2.8 \\
\hline \multicolumn{2}{|l|}{ Ethnicity } \\
\hline White & 51.4 \\
\hline African American & 48.6 \\
\hline \multicolumn{2}{|l|}{ Marital status } \\
\hline Married & 38.6 \\
\hline Divorced & 31.4 \\
\hline Separated & 5.7 \\
\hline Widowed & 10.0 \\
\hline Single & 10.0 \\
\hline Unmarried, living with partner & 2.9 \\
\hline Other & 1.4 \\
\hline \multicolumn{2}{|l|}{ Number of children } \\
\hline 0 & 20.6 \\
\hline 1 & 14.7 \\
\hline 2 & 36.8 \\
\hline 3 & 17.7 \\
\hline 4 & 4.4 \\
\hline 5 & 5.9 \\
\hline \multicolumn{2}{|l|}{ Education level } \\
\hline Less than HS & 0.0 \\
\hline HS & 11.4 \\
\hline Some college & 37.1 \\
\hline College graduate & 25.7 \\
\hline Postgraduate study & 22.9 \\
\hline Other & 2.9 \\
\hline \multicolumn{2}{|l|}{ Total family income } \\
\hline Less than $\$ 10,000$ & 9.0 \\
\hline$\$ 10,000-14,999$ & 6.0 \\
\hline$\$ 15,000-19,999$ & 9.0 \\
\hline$\$ 20,000-24,999$ & 4.5 \\
\hline$\$ 25,000-29,999$ & 4.5 \\
\hline$\$ 30,000-34,999$ & 3.0 \\
\hline$\$ 35,000-39,999$ & 10.5 \\
\hline$\$ 40,000-49,999$ & 13.4 \\
\hline$\$ 50,000-59,999$ & 3.0 \\
\hline$\$ 60,000-74,999$ & 16.4 \\
\hline More than $\$ 74,999$ & 20.9 \\
\hline \multicolumn{2}{|l|}{ Employment status } \\
\hline Unemployed & 45.7 \\
\hline Full-time & 41.4 \\
\hline Part-time & 12.9 \\
\hline
\end{tabular}

Table 1 (continued)

\begin{tabular}{lr}
\hline Variable & Valid \% \\
\hline Cancer treatments & \\
Surgery & 100.0 \\
Radiation & 76.3 \\
Chemotherapy & 77.6 \\
Hormone therapy & 72.4 \\
\hline
\end{tabular}

- What I have to do sometimes is have my son come over and pay my bills. Can you imagine? It really makes me feel bad...I've been so independent and here I am at 55 years old and I can't pay my bills. And the money's there.

- I just felt like I was getting scared that I would hurt myself...I [couldn't] remember if I looked at a stoplight. I felt like it was putting myself at risk.

- I have been so lost [while driving], I just pull over, and break down, and start crying. Because it's places I've been before and I know where I am going. It's terrible.

Responses from the medical community

One significant complaint that a majority of the interviewed women voiced was the lack of acknowledgement by the medical community when they complained about various symptoms of chemobrain. One respondent raised the issue of doctors' attitudes toward cognitive impairment with the women in her support group, and they concurred that doctors "poo-pooed" the condition and said, "'oh no there is no such thing." Another respondent became increasingly frustrated when no one on her medical team could seem to agree about what was happening to her: "it seems like most of [the doctors] are very insensitive, not all of them, but a lot of them just seem to not be able to hear what you are asking. Like I talked with maybe 6 radiation oncologists, and not one of them was agreeable to telling me what was going on." Other women reported that their doctors blamed their memory problems and other cognitive dysfunction on age; one participant said, "I talked to my doctor[s] about [the memory loss and loss of words] and what I would get was, 'You're getting older.' I mean, they sit there and give the odd nod to the fact that there was cognitive impairment but that I should be fine."

Many women wished they had received some warning. As one woman put it: "I really think it's the responsibility of the physicians to acknowledge or to inform people that you might have a short term memory." Another stated, "... you know, I wish that whether it's a doctor or a patient care coordinator or somebody, would sit down with a patient and talk to them [and say] 'You know, you may not get it, 
but these are some of the things that happen... just be aware, so that you don't get frightened that you are losing it or aren't meeting everybody's expectations."”

It is important to note that a smaller number of women did receive validation from their physicians when they brought up the various symptoms associated with chemobrain. How quickly doctors acknowledged patients' symptoms, however, varied. For example, Lucy, a high school graduate with two grown children, waited a long time:

My oncologist...finally admitted that chemo does affect your brain...he finally said it...all this time... he, you know, denied it... [I felt] vindicated because I knew my body. I knew that I was much more forgetful than I ever was, and I don't think that it would have been this enhanced just by age and... what I had been sharing, and not so much complaining about, but expressing concerns about, was finally acknowledged by my oncologist.

Another participant reported that her doctor simply stated that the cognitive dysfunction she was experiencing was a condition termed chemobrain, but offered no advice. She stated, "I talked about [my symptoms] with my oncologist and she said, "that's chemobrain"... [but] she really [hadn't] suggested doing anything about it." Jackie, a married mother of two, worked part-time. She fretted:

[My oncologist] noticed that I wrote on my hand, my notes, and he said, 'what are you doing that for?' And I go, 'you guys did this to me. I don't have my memory anymore.' He goes, 'well, do you think you have chemobrain?' I said, 'yeah...does it go away? Does it get better? Does it get worse? What's the deal?' And he says, 'we really don't know.' And I think that's the case. I think they really don't know. That's why nobody's sending you anywhere [for treatment.].

One woman reported a positive experience with her nurse and physician:

...I started to describe to her my sort of mental, I don't know what to call it, cognitive issues maybe... And I started to mention this... [to] the nurse and she just interrupted me and said, 'oh chemobrain... everybody gets that.' And I said, 'well, what are you talking about?' And then once she started talking to me about that, then I felt oh ok, this is something that other people share and this can get better. I didn't feel like I was going crazy or a sense of isolation about it or anything and then the doctor came in and we talked about it again. And we talk about it now when I go in. So I don't feel a sense of hostility from the medical profession or anything like that about it. I just feel that it's an under researched area....
Though this is the type of validation many women are seeking from their physicians for their symptoms, few in our study received it. This left many of them frustrated, scared, and unsure about what was happening to their minds.

Reactions of family and friends

The reactions of family and friends after the onset of symptoms vary from apathetic to supportive. Janet, a married mother of two, said her family did not take her complaints about her cognitive changes seriously, making her feel helpless:

I wish I could really talk to somebody who could really validate what I'm saying because my family, they kind of laugh. I feel that sometimes I desperately struggle to remember things. I don't know who to talk to. I've told everybody, but nobody [is offering any kind of help].

Another woman, Tammy, a divorced mother of two, reported that her teenage son, as well as others around her, began to challenge her authority:

Trust me, your children will take advantage of you because they'll say, 'but that's not what you said yesterday mom'... and I'm like, 'yeah, I think I said that.' And I had to stop saying 'I think I said that'... that was giving people [a window.] Everybody was coming back and telling me, "well, you didn't say that.' Yes, I did. That sounds like something I would have said...

Several women acknowledged that chemobrain confused their families and friends, especially young children. For example, one mother reported that her loss of words was a source of confusion for her children, who would often say, "mamma, what's wrong with you?" Even many adults could not understand the extent of the cognitive changes. Sharon stated:

If I'm out and I'll say something to someone, 'oh gosh, I'm sorry my memory's not really great.' People... say the silliest things in response. They don't think that you're really meaning it. They'll think, 'oh, mine too, oh whatever.' But you're just like, 'no really, I really...it's just not even funny.' And that's hard. I think that's really hard.

Sharon also reported that her friends seemed afraid when her symptoms seemed especially severe:

The brain is bad, the brain is embarrassingly bad. People that know me, I'm fine with. They all understand because they just have kind of gotten 
used to it. Though I think some of them are kind of afraid because sometimes it is really bad. Certain days are better than others... But it's embarrassing...

\section{Money and work}

Chemobrain can affect job performance. Because the ability to focus diminishes, duties become more difficult and often take longer to perform. Carrie, a school teacher, was a married mother of two teenagers at the time of her diagnosis. After her first chemotherapy treatment as well as a mastectomy, she and her husband divorced. After her treatment, Carrie felt she was easily distracted at work:

I find myself getting day dreamy. I am like the ADD kid: [I] can hyper-focus as long as [I am] doing one thing, but if something walks by down the hall, [and] I see it...I am gone. It makes my job a lot harder because as a teacher you have to do everything all at once. So when I leave at the end of the day, I am spent, when before I was energetic. And it's not a physical spent; it is a mental spent that I didn't used to have.

Respondents reported decreased efficiency and speed at work, thus reducing their chances of being promoted or assigned to projects, as they and their employers realize that they are no longer able to handle the level of work they were accustomed to pre-cancer treatment. Mary, a Pacific Bell employee, thought that "I got passed over for opportunities and [didn't get] the chances I would have normally gotten for advancement." She believed that this was due to her memory loss, which she said was starting to affect the quality and speed of her work. Another woman, Jill, a divorced mother of one, reported having to lie to her previous boss:

The memory loss... has sometimes been fairly significant. Certainly in my last job, my boss would say, 'remember that document we did last week?'...I would say, 'I think I remember. Give me a few more clues. Well, let me look.' And sort of try and fake it and hope that I would come up with the right thing.

Memory problems also often increased stress, especially in a professional environment. Laura, a post-doctoral research fellow, felt nervous conversing with colleagues after her symptoms started to become severe: “...it was a very sharp decline when the treatment started...I'm very insecure when I'm talking to people professionally because I'm worried I'm just going to draw a blank." Karen, a typist and clerk, became more hesitant about completing the work she was assigned and often called headquarters for clarification: "When I'm working at a situation I have to think about it...I have to call downtown to make sure I [am] doing the right thing... There's...hesitance... So I have to call [downtown] a lot; I call them almost everyday...I wasn't like this before." Another participant, a secretary, noticed: "I get frustrated easier. You know, I feel more stressed, like I'm at the counter and I'm working, you know, doing the filing, then all of a sudden, sometimes I draw a blank, like, what do I do next?" Charlotte, a single mother whose income supports two children, was forced to quit her job and find one with a lighter workload. As a result, her salary fell dramatically.

When I was diagnosed, I was the project manager for a \$24 million government project retrofitting military aircraft. I had thousands of engineering drawings and concepts in my head. I had names and phones numbers [and] figures. I had a mind like a steel trap. For the first three or four years after treatment I was totally useless. I couldn't even remember people's phone numbers... I'm still probably more efficient than the average fool, but I know that I'm different, which is one of the reasons that I'm working...a much less demanding job. I don't need to have the kind of technical expertise that I did in [my previous] position. So, I have the earning potential that's about $\$ 25-\$ 30,000$ less. And as a single mother of two children that becomes a real issue... And I have my sister who is a physician and friends who have MBAs from UCLA like I do who say, '...You could do anything. You don't have to have a job at this salary. You're earning nothing.' And I'm thinking, 'you know what? I'm really grateful to be earning anything at this point.'

Harriet, a married mother of three, was the manager of a large office. She took early retirement as a result of her cognitive impairment:

I went into retirement because of the cancer, simply because I could not maintain the level of work that I was used to... They came to me for everything. I had a big responsibility and I enjoyed it...after the cancer and going back to work, I couldn't sustain that. Every 2 hours, I was going somewhere to sit down and relax and could not think well...I couldn't coordinate everything that was going on. I couldn't do it anymore... With this memory thing I was very frustrated at work and so I thought that I can't go on like this. It was a chore now going to work than a joy. I just assessed the situation and said that it's not worth it.

Chemobrain also affected women who were job hunting. Some reported more severe symptoms in stressful situations like interviews. Others realized that such symptoms as memory loss prevented their ability to find employment. 
Laura, for example, stated: "I've been job hunting the last 3 years and it's extremely stressful to go to interviews knowing that I have these memory issues...I'm just not as sharp as I was...I used to be able to think on my feet really well, and that's gone, that edge is just totally gone now." Women attempting to complete degrees in order to (re)enter the job market were also disadvantaged by chemobrain symptoms. Emily noted:

I started going to school about the same time as I started my cancer treatment...I'm studying French... It feels so different to me from how I was before... It's as if I can't grasp what the teacher is saying. I listen very carefully. I concentrate, but I feel like it doesn't get into my brain. It feels like something isn't quite working in my brain the way it used to...it's harder for me to process new verbal material. It seems to be a verbal intake problem on that level... and I watch the other students and I see that it's different for me than it is for them.

Laura suffered a major setback when writing her dissertation because cognitive impairment affected her ability to read. After having worked as an attorney for 15 years, managing a law firm in a major Midwestern city, she quit her job and enrolled in a PhD program, during which she was diagnosed with breast cancer. She described herself as once being ambitious and competitive, yet after her first year of treatment, she no longer had that same drive. She stated, “...When I began the chemo... I couldn't concentrate at all and I couldn't read for about the first year. I think I read one novel during that entire time. I read no academic material. I couldn't work. I couldn't write. The following year I needed to finish my Ph.D. and it was...extremely hard, and I felt I couldn't concentrate adequately."

\section{Coping}

Women devised various ways to deal with the symptoms of chemobrain. Some kept journals to record everything they needed to do. One participant used calendars: “...I have to write down an awful lot to make myself remember. My calendar is filled up with what I should and shouldn't do each day, so I can keep up with things." Another woman reported: "I have Post-its all over my refrigerator, all over my mirror and everywhere." In fact, the most common method used by women is Post-its, with some covering walls in their homes with reminders for typically mundane tasks such as "turn off the gas" or "remember to close front door." Still others trained themselves to put objects, such as keys, in specific places. One participant stated: “....when I get out of the car, I tell myself to secure the keys, make sure you put the keys in the right place. When I get home, I immediately put the keys in a specific place. I misplace everything."
Other women tried to counteract the effects of chemotherapy by keeping their minds active. One respondent started doing problems out of the workbooks that she bought for her niece: “...I do a lot of the math and the cognitive problems...And I find if I keep my mind moving and learning that it's getting better." Katherine considered a more drastic step: "I have a long-term project... going back to school... And I think the more I push myself, the more I will gain back. I mean, I have heard that the people do get brain function back and there [is] a lot of research that, in fact, brain cells do [regenerate]...."

For some, coping means having to significantly curtail work and social activities. Charlotte, who took a lower paying job to reduce stress, decided to avoid certain social occasions. "I don't put myself in situations where I have to worry about my memory or ability. I don't think I'd go to a fancy party at the Music Center with my friend who is a composer even though she has invited me because I don't think I'd be able to handle the conversation. I think I'm quieter than I used to be."

Other women, however, have more or less accepted the limitations that the cognitive impairment puts on their lives and resigned themselves to a diminished cognitive capacity. Laura has come to terms with her memory loss: "I don't even bother to listen to people's names anymore because I know I won't remember them. So I don't even try..." Maryanne, a college graduate and mother of one, simply told people that she had memory problems, so if they want her to remember something, it is their responsibility to remind her:

I've just made [my memory] into a game. I don't worry about it if I don't remember...I tell people up front that I don't remember well, so if it's something important to [them], [I tell them to] call me several times. With my daughter, I've told her that she is very important to me, but I don't remember well. If it's important, you have to send it to me in a letter so I can put it on the refrigerator or tell it to me time and time again. I tell her that if I don't remember it, I'm not going to let [her] beat me up because I didn't remember it...so even though my memory is very bad, I don't let it get me down and I just turn it around and make it comical and do other things with it... even though I know it's major.

Another woman stated, "At the support group, we joke about it and call it chemobrain. We write each other notes so we don't forget to say things and it's just the way it is." As another woman put it, "I hold on to the moment because I don't have the ability to hold on to memories."

\section{Discussion}

The qualitative data discussed in this paper underscore the very serious ways in which chemobrain can affect the life 
experiences of cancer survivors. Chemobrain is only one of the many post-treatment symptoms that survivors of cancer experience. Thus, although medical science has developed adequately aggressive cancer treatments that result in greatly diminished mortality from the disease, the cures may be adversely affecting the lives of survivors. Research continues to unfold in this arena, especially as researchers try to discover the specific mechanisms behind chemobrain and other post-treatment symptoms, and the mass media have begun to widely acknowledge the phenomenon, increasing society's awareness of the condition. This progress in both the scientific community and in society at large is crucial to the understanding of chemobrain and its psychosocial effects.

A clear understanding of the cognitive impairments experienced by survivors through detailed interviews and documentation will aid researchers in developing targeted therapies and interventions aimed at improving or mitigating these post-treatment side effects. It is difficult to truly understand the life changes these women have undergone without hearing first-hand accounts of their experiences. Data obtained from questionnaires cannot fully convey the experience of cognitive limitation and its relationship to daily functioning as perceived by the survivor herself the way an in-depth interview can. Without these more detailed accounts, it is difficult for the nurses, physicians, and researchers working with these patients to obtain a full understanding of the clinical picture necessary to develop effective interventional strategies. It is also essential to educate family members, as well as survivors themselves, that the cognitive changes being seen are not unexpected or uncommon in a chemotherapy population, thus helping survivors and their families cope by reading the accounts of others experiencing a similar reality. Our study also points out that the need for spreading awareness and developing effective interventions and therapies is not purely for the emotional and psychological well being of survivors, but for economic purposes as well. The impact of cognitive changes on the financial stability of patients and their families can be quite significant as seen in the accounts of our study participants. Many women are unable to function at the same level professionally, to complete their educations, or to keep their jobs, thereby profoundly affecting their financial security, particularly if they are the sole providers in their households.

Despite the large number of women who report cognitive impairment and functional decline, several papers have published data suggesting that there is a discrepancy between the cognitive decline women perceive and what objective cognitive assessments show [21,31]. This does not mean that breast cancer survivors are overestimating their degree of cognitive impairment, but rather, may mean that the current neuropsychological batteries used in the assessment of these women are not sensitive enough to detect the changes in functioning that they experience. The stories we gathered in our interviews show the various changes in memory, concentration, and thinking ability that they have experienced since chemotherapy. The fact that certain assessments cannot appreciate these changes does mean not they do not exist; this is why in-depth interviews of survivors are important. Such reports are necessary to show the true cognitive impact of chemotherapy and to help guide the development of measures that can detect the cognitive changes these women describe. Downie et al. [31] state that many measures of cognitive assessment, such as the High Sensitivity Cognitive Screen, are not relevant to daily functioning and describe a 1999 study by Sbordone and Guilmette which showed that few neuropsychological tests "had been designed to simulate real life situations and that no assessment adequately predicted everyday function." Thus, interview data, such as ours, are critical in highlighting exactly why we need to develop neurocognitive batteries that can better detect subtle changes in cognitive functioning.

This study, however, does suffer from several limitations. A larger sample size drawn from a random, national pool of survivors would help to clarify the experiences of the broader population of survivors; this study, as a pilot, relied upon a non-random sample that self-nominated for the study and that self-reported cognitive impairment. The inclusion of more empirical measures of cognitive function administered both pre- and post-treatment, albeit potentially limited in their ability to fully assess the scope of cognitive decline, would have added an additional layer of useful data in our quest to understand the extent and impacts of chemobrain. Future studies should also purposively include women of other ethnicities beyond the African American and Caucasian women included here.

As more and more people survive cancer long term, and our understanding of these phenomena improve, the amelioration of post-treatment quality of life for survivors will pose a significant challenge. Central to informing this effort will be greater knowledge through expanded research in this field and a heightened focus on the interplay between chronic conditions such as chemobrain and resultant life experience.

Open Access This article is distributed under the terms of the Creative Commons Attribution Noncommercial License which permits any noncommercial use, distribution, and reproduction in any medium, provided the original author(s) and source are credited.

\section{References}

1. National Cancer Institute. Estimated US cancer prevalence. Updated May 13, 2009. Available from: http://cancercontrol. cancer.gov/ocs/prevalence/prevalence.html. 
2. American Cancer Society. What are the key statistics for breast cancer? Detailed Guide, Breast Cancer 2009; Available from: http:// www.cancer.org/docroot/CRI/content/CRI_2_4_1X_What_are the_key_statistics_for_breast_cancer_5.asp.

3. Grober SE. Resources for treatment of chemotherapy-related cognitive difficulty. Cancer Pract. 2002;19:216-8.

4. Wienke MH, Dienst E. Neuropsychological assessment of cognitive functioning following chemotherapy for breast cancer. Psychooncology. 1995;4:61-6.

5. Schagen SB, Van Dam FS, Muller MJ, Boogerd W, Lindeboom J, Bruning PF. Cognitive deficits after postoperative adjuvant chemotherapy for breast carcinoma. Cancer. 1999;85:640-50.

6. Van Dam FS, Schagen SB, Mueller MJ, Boogerd W, van der Wall E, Droogleever Fortuyen ME, et al. Impairment of cognitive function in women receiving adjuvant treatment for high-risk breast cancer: high-dose vs. standard-dose chemotherapy. J Natl Cancer Inst. 1998;90:182-3.

7. Brezden CB, Phillips KA, Abdolell M, Bunston T, Tannock IF. Cognitive function in breast cancer patients receiving adjuvant chemotherapy. J Clin Oncol. 2000;18:2695-701.

8. Ahles TA, Saykin AJ, Furstenberg CT, Cole B, Mott LA, Skalla K, et al. Neuropsychologic impact of standard-dose systemic chemotherapy in long-term survivors of breast cancer and lymphoma. J Clin Oncol. 2002;20:485-93.

9. Castellon SA, Ganz PA, Bower JE, Petersen L, Abraham L, Greendale GA. Neurocognitive performance in breast cancer survivors exposed to adjuvant chemotherapy and tamoxifen. J Clin Exp Neuropsychol. 2004;26:955-69.

10. Shilling V, Jenkins V, Morris R, Deutsch G, Bloomfield D. The effects of adjuvant chemotherapy on cognition in women with breast cancer-preliminary results of an observational longitudinal study. Breast. 2005;14:142-50.

11. Bender CM, Sereika SM, Berga SL, Vogel VG, Brufsky AM, Paraska KK, et al. Cognitive impairment associated with adjuvant therapy in breast cancer. Psycho-Oncology. 2006;15:422-30.

12. Hurria A, Rosen C, Hudis C, Zuckerman E, Panageas KS, Lachs MS, et al. Cognitive function of older patients receiving adjuvant chemotherapy for breast cancer: a pilot prospective longitudinal study. J Am Geriatr Soc. 2006;54:925-31.

13. Raffa RB, Duong PV, Finney J, Garber DA, Lam LM, Matthew SS. Is chemo-fog/chemo-brain caused by cancer chemotherapy? J Clin Pharm Ther. 2006;31:129-38.

14. Silverman DH, Dy CJ, Castellon SA, Lai J, Pio BS, Abraham L, et al. Altered frontocortical, cerebellar, and basal ganglia activity in adjuvant-treated breast cancer survivors 5-10 years after chemotherapy. Breast Cancer Res Treat. 2007;103:303-11.

15. Nelson CJ, Nandy N, Roth AJ. Chemotherapy and cognitive deficits: mechanisms, findings, and potential interventions. Palliat Support Care. 2007;5:273-80.

16. Kannarkat G, Lasher EE, Schiff D. Neurologic complications of chemotherapy agents. Curr Opin Neurol. 2007;20:719-25.

17. Tangpong J, Cole MP, Rukhsana S, Estus S, Vore M, St. Clair W, et al. Adriamycin-mediated nitration of manganese superoxide dismutase in the central nervous system: insight into the mechanism of chemobrain. J Neurochem. 2007;100:191-201.

18. Jackson GE. Chemo brain - a psychotropic drug phenomenon? Med Hypotheses. 2008;70:572-7.

19. Wefel J, Lenzi R, Theriault R, Buzdar A, Cruickshank MC. 'Chemobrain' in breast carcinoma? A prologue. Cancer. 2004;101:466-75.

20. Donovan K, Small B, Andrykowski M, Schmitt F, Munster P, Jacobsen P. Cognitive functioning after adjuvant chemotherapy and /or radiotherapy for early-stage breast carcinoma. Cancer. 2005;104:2499-507.

21. Jenkins V, Shilling V, Deutsch G, Bloomfield D, Morris R, et al. A 3-year prospective study of the effects of adjuvant treatments on cognition in women with early stage breast cancer. $\mathrm{Br} \mathrm{J}$ Cancer. 2006;94:828-34.

22. Shilling V, Jenkins V. Self-reported cognitive problems in women receiving adjuvant therapy for breast cancer. Eur J Oncol Nursing. 2007;11:6-15.

23. Hurria A, Somlo G, Ahles T. Renaming "chemobrain". Cancer Invest. 2007;25(6):373-7.

24. Falleti MG, Sanfilippo A, Maruff P, Weih L, Phillips KA. The nature and severity of cognitive impairment associated with adjuvant chemotherapy in women with breast cancer: a metaanalysis of the current literature. Brain Cogn. 2005;59:60-70.

25. Matsuda T, Takayama T, Tashiro M, Nakamura Y, Ohashi Y, Shimozuma K. Mild cognitive impairment after adjuvant chemotherapy in breast cancer patients - evaluation of appropriate research design and methodology to measure symptoms. Breast Cancer. 2005;12:279-87.

26. Bender CM, Paraska KK, Sereika SM, Ryan CM, Berga SL. Cognitive function and reproductive hormones in adjuvant therapy for breast cancer: a critical review. J Pain Symptom Manage. 2001;21:407-24.

27. Gross J. Chemotherapy is no longer ignored as illusion. The New York Times; 29 Apr 2007.

28. Hoag H. The foggy world of chemobrain. The Toronto Star; 3 Nov 2007.

29. Breast cancer: new software program helps breast cancer survivors and patients fight chemofog. Drug Week; 19 Oct 2007.

30. Fitch MI, Armstrong J, Tsang S. Patients' experiences with cognitive changes after chemotherapy. Can Oncol Nurs J. 2008;18 (4):180-92.

31. Downie FP, Mar Fan HG, Houédé-Tchen N, Yi Q, Tannock IF. Cognitive function, fatigue, and menopausal symptoms in breast cancer patients receiving adjuvant chemotherapy: evaluation with patient interview after formal assessment. Psychooncology. 2006;15(10):921-30.

32. Crabtree BF, Miller WL. Doing qualitative research. Sage: Newbury Park; 1992.

33. University of Rochester Medical Center. $82 \%$ of cancer patients report 'chemo brain' during, after treatment. Press release, June 5, 2006. Available from http://www.urmc.rochester.edu/pr/News/story. cfm?id=1141. 